\title{
Rightsizing lung cancer surveillance
}

\author{
Farhood Farjah, MD, MPH, ${ }^{a}$ and Larry Kessler, $\mathrm{ScD}^{\mathrm{b}}$
}

From the ${ }^{\mathrm{a}}$ Departments of Surgery and ${ }^{\mathrm{b}}$ Health Services, University of Washington, Seattle, Wash.

Disclosures: Authors have nothing to disclose with regard to commercial support.

Received for publication Oct 10, 2018; accepted for publication Oct 10, 2018; available ahead of print Nov 30, 2018.

Address for reprints: Farhood Farjah, MD, MPH, Department of Surgery, University of Washington, 1959 NE Pacific St, Box 356310, Seattle, WA 98195 (E-mail: ffarjah@uw.edu).

J Thorac Cardiovasc Surg 2019;157:1194-5

$0022-5223 / \$ 36.00$

Copyright $\subset 2018$ by The American Association for Thoracic Surgery

https://doi.org/10.1016/j.jtcvs.2018.10.046

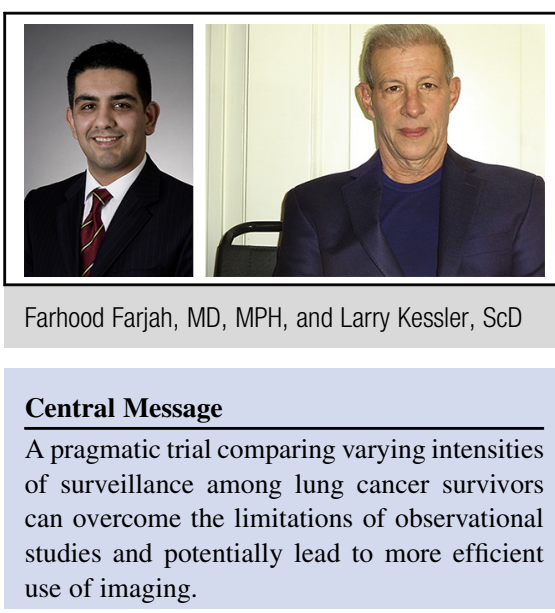

See Articles pages 1196 and 1205 .
Among patients who undergo operations for lung cancer, the risk of recurrence peaks during the first 2 years after surgery and the risk of a new primary lung cancer is substantially higher than in the general population. ${ }^{1}$ The intent of surveillance imaging is to detect both recurrent and new lung cancers early — when the disease is curable.

Two investigations provide evidence that surveillance imaging may be beneficial. Both studies report high rates of early detection, high rates of treatment for recurrence or new primary lung cancer, and high 5-year survival rates for treated patients. ${ }^{2,3}$ The study by Wang and colleagues ${ }^{2}$ also provides a novel description of prevalent (ie, synchronous) lung cancers among survivors undergoing surveillance. ${ }^{2}$ However, the investigation by Subramanian and colleagues $^{3}$ - using a unique data source consisting of tumor registry (not administrative) data supplemented by human chart abstraction-reveals no relationship between survival and the intensity of surveillance. This finding sounds a cautionary note about the possible benefits of intense imaging surveillance.

Despite the strengths of these 2 carefully conducted investigations, the evidence base supporting lung cancer surveillance remains weak due to the limitations of observational study designs. Limitations such as lead and length time bias, confounding, and time-varying surveillance imaging are examples of potential threats to the validity of observational studies. ${ }^{4,5}$

A randomized trial can overcome these limitations if we can agree on the most important question to answer. Preliminary findings from a French trial randomizing patients to computed tomography (CT) versus chest radiograph surveillance showed no effect of surveillance on survival. ${ }^{6,7}$ There is likely no appetite for repeating a similar trial given prevailing, strong beliefs in North America in favor of surveillance imaging with $\mathrm{CT}$. Although there is no evidence to date that surveillance imaging causes patient harm, it is possible that we overutilize imaging without any benefit to patients. A trial could be conducted to compare outcomes across 2 extremes of surveillance intensity (eg, CT every 3 vs 12 months [8 vs 2 scans over a 2 -year surveillance period] with annual follow-up imaging thereafter in both groups). Contrasting 2 extremes is more likely to reveal an effect of surveillance imaging on survival if one really exists. Such a trial would close a significant knowledge gap over the optimal intensity of surveillance imaging, and therefore have a large influence on the delivery of lung cancer care. However, such a trial would be expensive. A value-of-information analysis estimates the return on investment from conducting a study like that and may provide the justification to move forward with a large, multicenter pragmatic trial. ${ }^{8}$ Given how much we have learned from investigations such as the National Lung Screening Trial and the National Emphysema Treatment Trial, ${ }^{9,10}$ thoracic surgeons should provide the leadership and advocacy necessary to pursue a lung cancer surveillance trial.

\section{References}

1. Lou F, Huang J, Sima CS, Dycoco J, Rusch V, Bach PB. Patterns of recurrence and second primary lung cancer in early-stage lung cancer survivors followed with routine computed tomography surveillance. J Thorac Cardiovasc Surg. 2013;145:75-81.

2. Wang Y, Yeung J, Hanna WC, Allison F, Paul NS, Waddell TK, et al. Metachronous or synchronous primary lung cancer in the era of computed tomography surveillance. J Thorac Cardiovasc Surg. 2019;157:1196-202.

3. Subramanian M, Liu J, Greenberg C, Schumacher J, Chang GJ, McMurry TL, et al. Imaging surveillance for surgically resected stage 1 non-small cell lung cancer: is more always better? J Thorac Cardiovasc Surg. 2019;157:1205-17.

4. Weiss NS, Rossing MA. Healthy screened bias in epidemiologic studies of cancer incidence. Epidemiology. 1996;7:319-22.

5. Chubak J, Boudreau DM, Wirtz HS, McKnight B, Weiss NS. Threats to validity of nonrandomized studies of postdiagnosis exposures on cancer recurrence and survival. J Natl Cancer Inst. 2013;105:1456-62.

6. Westeel V, Lebitasy MP, Mercier M, Girard P, Barlesi F, Blanchon F, et al. IFCT0302 trial: randomised study comparing two follow-up schedules in completely resected non-small cell lung cancer. Rev Mal Respir. 2007;24:645-52. 
7. ESMO 2017 Press Release: IFCT-0302 results question role of CT-scan in NSCLC post-surgery follow-up. Available at: https://www.esmo.org/ Conferences/Past-Conferences/ESMO-2017-Congress/Press-Media/Press-Releases/ IFCT-0302-results-question-role-of-CT-scan-in-NSCLC-post-surgery-follow-up. Accessed October 25, 2018.

8. Ramsey SD, Blough DK, Sullivan SD. A forensic evaluation of the National Emphysema Treatment Trial using the expected value of information approach. Med Care. 2008;46:542-8.
9. National Lung Screening Trial Research Team, Aberle DR, Adams AM, Berg CD, Black WC, Clapp JD, Fagerstrom RM, et al. Reduced lung-cancer mortality with low-dose computed tomographic screening. N Engl J Med. 2011;365: 395-409.

10. Fishman A, Martinez F, Naunheim K, Piantadosi S, Wise R, Ries A, et al. A randomized trial comparing lung-volume-reduction surgery with medical therapy for severe emphysema. N Engl J Med. 2003;348: 2059-73. 